\title{
A VACINAÇÃO COMPULSÓRIA SEGUNDO O DIREITO PÚBLICO E O MOVIMENTO ANTIVACINA
}

\author{
COMPULSORY VACCINATION UNDER PUBLIC LAW AND THE ANTIVACCINE \\ MOVEMENT
}

\author{
Ursula Eustórgio Oliveira de Azevedo ${ }^{1}$
}

\begin{abstract}
RESUMO: O Estudo apresentado tem como o objetivo reconhecer a importância da vacinação compulsória da população brasileira e o questionamento sobre o crescente movimento antivacina. O método utilizado foi de abordagem dedutiva embasado em procedimento bibliográfico, voltado para a pesquisa exploratória e documental com base nos princípios de sustentação de normas jurídicas. A relevância e originalidade da discussão jurídica é imprescindível pela sociedade atual levando em consideração o respeito à vida de todos os brasileiros de maneira geral. Os resultados positivos das atividades de vacinação no mundo estão comprovando a eficácia de paralisação de propagação da doença de coronavírus 2019 -COVID-19, SARS-CoV-2 de acordo com a Organização Mundial da Saúde (OMS). A importância da conscientização social, com responsabilidade cidadã por meio do respeito e aplicação das normas referentes à saúde pública na Constituição Federal de 1988 como contribuição teórica e metodológica.
\end{abstract}

Palavras-chave: Vacinação compulsória. Movimento antivacina. Saúde pública. Responsabilidade consciente e cidadania na saúde.

ABSTRACT: The present study aims to recognize the importance of compulsory vaccination of the Brazilian population and the question concerning the growing antivaccine movement. The method of this research was the deductive approach using a bibliographic procedure and focused on exploratory and documentary research based on the principles of the support of legal norms. The relevance and originality of the legal discussion are essential for current society considering respect for the life of all Brazilians in general. According to the World Health Organization (WHO), the positive results of vaccination activities around the world are proving the effectiveness of stopping the spread of coronavirus disease 2019 (COVID-19, SARS-CoV-2). The importance of social awareness, with citizen responsibility through respect and application of the norms regarding public health found in the 1988 Federal Constitution, is demonstrated, and provides a theoretical and methodological contribution to the literature.

Keywords: Compulsory vaccination. Antivaccine movement. Public health. Conscious responsibility. Civic duty in health.

\footnotetext{
' Professora de Direito Administrativo, Direito Internacional e Direitos Humanos, Direito Constitucional, Direito Ambiental. Especialização em Direito Processual Civil pela Universidade Cândido Mendes UCAM - RJ. Especialização em Advocacia Trabalhista e Previdenciária pela Universidade Cândido Mendes - UCAM - RJ. Especialização em Direito Público pela Faculdade Legale- SP. Especialização em Advocacia Extrajudicial pela Faculdade Legale-SP. Especialização em Direito Constitucional Aplicado pela Faculdade Legale- SP. Especialização em Direito Internacional e Direitos Humanos pela Pontifícia Universidade Católica de Minas Gerais PUC-MG (Cursando). Advogada. Graduação em Direito pela Universidade Estácio de Sá - UNESA - RJ. E-mail:_ursulalink@gmail.com
} 


\section{CONSIDERAÇÕES INICIAIS}

A Constituição Federativa do Brasil de 1998, explicita a liberdade individual de todos os seus cidadãos conforme o artigo $5^{\circ}$, inciso II onde ninguém será obrigado a fazer ou deixar de fazer alguma coisa senão em virtude de lei e o inciso VIII, assegura que ninguém será privado de direitos por motivo de crença religiosa ou de convicção filosófica ou política, salvo se as invocar para eximir-se de obrigação legal a todos imposta e recusarse a cumprir prestação alternativa, fixada em lei.

Acordando com a interpretação combinada dos referidos incisos infere-se que o limite da autonomia individual de uma família, em relação à vacinação obrigatória, é a Lei, o próprio comando normativo inserto no Estatuto da Criança e do Adolescente que, em seu artigo I4, $\AA^{\circ}$ o estabelece a obrigatoriedade da vacinação, nos casos recomendados pelas autoridades sanitárias. Portanto, o Programa Nacional de Imunização do Ministério da Saúde no Brasil (PNI/MS), que estabelece o cronograma de vacinação infantil obrigatória, dá efetividade ao ECA e deve ser concebido como verdadeiro instrumento de proteção da vida e da saúde da criança e do adolescente imunizantes.

Conforme estabelecido na Constituição Federal, o texto fundamental aborda direitos dos cidadãos que devem ser protegidos pelo Estado. No caso do Art. $6^{0}$ da Constituição Federal de 1988, estabelece que a saúde é um direito social. No artigo 196 da Constituição Federal de 1988, explicita que a saúde é direito de todos e dever do Estado, garantido mediante políticas sociais e econômicas que visem à redução do risco de doença e de outros agravos e ao acesso universal e igualitário às ações e serviços para sua promoção, proteção e recuperação. Na legislação pública vigente a vacinação pode ser obrigatória, considerando essa previsão constitucional. O debate é o direito de todas as pessoas à saúde estar colidindo com outros direitos. Especialmente no caso de pandemias, um dos argumentos que tem se levantado é a liberdade individual, do negacionismo em não aceitar e admitir a necessidade de vacinação, pelo bem comum, afetando a liberdade de escolha. Existe nesse ponto dois direitos fundamentais que estão previstos na Constituição Federal e que são contrapostos no caso específico. A Constituição não estabelece nenhuma prevalência de um sobre o outro, mas no caso concreto há a necessidade do entendimento de qual deva prevalecer. Há um caminho que precisa ser protegido, o da saúde pública e no 
outro caminho a proteção do direito individual de pessoas que querem se negar a isso. É válida a constatação de que o direito à saúde pública, ao supremo direito à vida coletiva e a obrigação a se vacinar respeitando ao convívio social deveriam prevalecer frente a supostas liberdades individuais.

\section{SAÚDE COLETIVA}

A saúde constitui direito fundamental, de natureza social, conforme preceitua o art. 6o- caput, da Constituição Federal e está associada intensamente ao princípio da dignidade da pessoa humana, um dos pilares da República Federativa do Brasil.

A Constituição Federal de 1988 explicita claramente em seu Art. 196 que a saúde é direito de todos e dever do Estado, garantido mediante políticas sociais e econômicas que visem à redução do risco de doença e de outros agravos e ao acesso universal e igualitário às ações e serviços para sua promoção, proteção e recuperação.

Ainda no artigo 23, inciso II, da Carta Magna do Brasil, confere competência comum à União, aos Estados, ao Distrito Federal e aos municípios nos cuidados da saúde e assistência pública, reforçando o aspecto da responsabilidade de cada ente federativo e de todos, consoante a responsabilidade solidária.

Instituída na Constituição Federal de 1988 está a obrigação do Estado em prover o acesso às ações e serviços de saúde, organização sistematizada, as diretrizes, a participação complementar da rede privada afirmando algumas das atribuições de atendimento do Sistema Único de Saúde.

Destarte a Lei Orgânica da Saúde, Lei no 8080 de 19 de setembro de $1990^{2}$ indica as condições de promoção, proteção e recuperação da saúde, da organização e do funcionamento desses serviços. Dentro dessa normativa esclarece que a saúde é um direito fundamental do ser humano, devendo o Estado prover as condições indispensáveis ao seu pleno exercício. Essa diretriz determina que todos têm direito à Saúde, por isso, o Sistema Único de Saúde (SUS) deve ser considerado universal. Para que o Estado garanta essa saúde, há que desenvolver, formular e executar políticas econômicas e sociais que abranja a todos de modo imparcial. Desse regimento encontra-se os fatores determinantes e

${ }^{2}$ Lei 8080/9o < http://www.planalto.gov.br/ccivil_03/leis/1808o.htm> acesso em I2 de maio de 202I. 
condicionantes da saúde, como: educação, lazer, moradia, saneamento, transporte e outros. Igualmente, a saúde está compreendida não apenas como ausência de doença, mas a soma de uma série de fatores que, integrados, promovem o bem-estar. Qualquer tratamento médico adequado aos necessitados sociais está inserido no rol dos deveres do Estado, na área de saúde. O acesso aos serviços de saúde do Sistema Único de Saúde (SUS) está disponível para os mais de 200 milhões de habitantes do Brasil. No Sistema Único de Saúde (SUS) estão o Serviço de Atendimento Móvel de Emergência- SAMU, as unidades hospitalares gratuitas, a atenção farmacêutica, a regulamentação da indústria e mais uma série de serviços e ações norteadas por princípios doutrinários e organizativos.

As concepções que regem e norteiam as ações do setor de saúde no Brasil são divididas em dois tipos: princípios doutrinários e princípios organizativos. Os princípios dos doutrinários encontram-se a universalidade, integralidade e equidade.

A universalidade institui que todo cidadão tem direito à saúde e acesso a todos os serviços públicos de saúde. Além disso, o governo tem o dever de prover assistência à saúde igualitária para todos. A integralidade detalha que todas as pessoas devem ser atendidas desde as necessidades básicas, de forma integral. A integralidade trabalha em todo o ciclo vital do ser humano, do nascimento até a morte. Esse princípio foca na prevenção e reabilitação da saúde. É preciso ter ações preventivas antes de o ser humano adoecer e precisar de cuidados médicos. A equidade observa que toda pessoa é igual perante o SUS. Contudo, esse princípio não significa prover os mesmos serviços de saúde para todos, pois o atendimento deve ser realizado de acordo com a necessidade de cada um. Essa caraterística é influenciada pelas particularidades, pelo perfil epidemiológico, pelos agravantes de saúde de cada região. Os municípios, os estados ou o governo federal devem trabalhar de acordo com as necessidades de cada região, para que seja contemplada com os serviços de saúde pública de que realmente precisa.

Dentre as ações na gestão do sistema de saúde, estão estabelecidos os princípios do organizativos do Sistema Único de Saúde (SUS). Esses princípios, a descentralização, a regionalização, a hierarquização e a participação social que operacionalizam as ações de saúde baseadas na universalidade, integralidade e equidade. 
A descentralização no Sistema Único de Saúde (SUS) é considerada um dos princípios-base. Promove a redistribuição do poder e das responsabilidades, em direção única, de forma articulada e integrada, nas três esferas do governo: municipal, estadual e federal. Com esse princípio, o município reconhece as necessidades da região e tem autonomia para implementar medidas, especialmente nas unidades de saúde, que vão ao encontro das necessidades da sua população. Na regionalização as estratégias de saúde devem funcionar com uma articulação a serviços de saúde já existentes em uma região, conforme o município que tem uma infra-estrutura mais adequada para o atendimento à saúde realiza atendimentos para outros municípios. Esses serviços são adquiridos em forma de convênios de saúde. Já a hierarquização possui a função de viabilizar a forma de acesso aos serviços de rede ambulatorial de alta, média e baixa complexidades, dependendo de cada caso. Na participação social está formatada conforme a Lei no 8.142/9033, indicando por meio da efetivação dos conselhos de saúde - locais, municipais, regionais, estaduais e nacional - sobre a realização de conferências de saúde, o Poder Público e a sociedade buscam formular estratégias e controlar e avaliar toda a execução da política de saúde nas esferas do governo.

O Decreto 7.508 de 28 de Junho de $20{ }^{4}{ }^{4}$ é a legislação mais nova do Sistema Único de Saúde que regulamenta a Lei 8.080/9o, dispondo acerca de regiões de saúde, contratos organizativos de ações públicas, comissões intergestoras, mapa da saúde no Brasil, rede de atenção à saúde, serviços especiais de acesso aberto, protocolo clínico e diretrizes terapêuticas com introdução a relatórios específicos controlados como a Relação Nacional de Ações e Serviços de Saúde (RENASES), e Relação Nacional de Medicamentos Essenciais (RENAME).

\section{CONTEXTO HISTÓRICO SOBRE VACINAÇÃO NO BRASIL}

São bem antigas as polêmicas em torno das Campanhas Vacinais e sua eficácia. O tema já nos anos de 1900, houve manifesto popular que ficou conhecido como "Revolta da Vacina”, em que a população, sem informações dos benéficos da imunização, manifestou-

\footnotetext{
${ }^{3}$ Lei no 8.142/90< http://www.planalto.gov.br/ccivil_03/leis/18142.htm> acesso em o8 de maio de 2021. ${ }^{4}$ Lei no 8.142/90 < http://www.planalto.gov.br/ccivil_03/_ato201I-2014/201I/decreto/d7508.htm> acesso em I2 de maio de 2021.
} 
se contra a vacinação compulsória. As brigadas sanitárias da época adentravam as casas e vacinavam as pessoas sem o consentimento delas. Mesmo com a oposição dos meios de comunicação da época e da manifestação popular, Oswaldo Cruz foi o responsável pela medida radical e obrigatória e acabou por ocupar uma posição política que lhe possibilitou trabalhar na estruturação da Saúde Pública do Brasil. Oswaldo Cruz então assumiu a Diretoria Geral de Saúde Pública, cargo que na época equivalia ao de ministro da Saúde, e torna a cidade do Rio de Janeiro um grande laboratório de combate a doenças infectocontagiosas.

Em II de novembro de 1904, explodiu o motim popular cujo caos e as depredações tomaram conta da cidade do Rio de Janeiro por uma semana. Pelotões do governo disparavam contra a multidão na tentativa de controlar a situação. O movimento "Revolta da Vacina"s deixou um saldo negativo de 23 mortos, 67 feridos, além de 945 pessoas presas, transferidas para o estado do Acre e submetidas a trabalhos forçados. O movimento se justificou não só pela obrigatoriedade da vacinação, mas também pela falta de informação sobre os efeitos que a vacina causaria. Em 1904, uma lei tornava obrigatória a vacina contra a varíola. A questão da obrigatoriedade de vacinação colocou em posições antagônicas o sanitarista Oswaldo Cruz e a Águia de Haia, Rui Barbosa no século passado. Dentre aqueles que não queriam colocar dentro do corpo o vírus da própria doença, estava Rui Barbosa que em sua individual opinião, a vacina não era inofensiva. Pelo contrário, Rui Barbosa considerava a vacina como um veneno onde era introduzido um vírus no corpo que poderia ser o condutor da moléstia e da morte.

Depois da morte de Oswaldo Cruz, em fevereiro de 1917, Rui Barbosa, em um discurso proferido no Teatro Municipal, acabou reconhecendo a importância do sanitarista, dando a ele o epíteto de "pasteur dos trópicos".

No Brasil, algumas doenças erradicadas e controladas com a adesão às vacinas, por campanha de imunização: varíola (1973), poliomielite (1989), sarampo (2016) e a redução da difteria, coqueluche, tétano neonatal e acidental. Com o crescimento do movimento antivacina, houve um surto em 2018 de sarampo, assim como a poliomielite corre grande perigo de reintrodução em pelo menos 312 cidades brasileiras.

\footnotetext{
${ }^{5}$ Revolta da Vacina < https://portal.fiocruz.br/noticia/revolta-da-vacina-2> acesso em ro de maio de 202I.
} 
Nos dias atuais, mais do que a desinformação, as informações falsas nas mídias sociais induzem a um novo movimento antivacina. Associada à falta de informação, as fakes news disseminadas pelas influentes mídias digitais contribuem com a queda nas taxas de cobertura vacinal. E, o efeito da não vacinação, sem dúvida, gera um grande impacto epidemiológico provocando o ressurgimento de doenças já também erradicadas no Brasil, como o sarampo, poliomielite, difteria e rubéola que voltam a ameaçar a saúde pública brasileira. Principalmente no combate a atual pandemia propagação da doença de coronavírus 2019 -COVID-19, SARS-CoV-2, e suas variantes. Os profissionais da saúde devem assumir o papel de divulgar informações verídicas como os benefícios da vacinação, com embasamento científico sobre o tema, com compromisso ético e profissional junto à sociedade. E a sociedade por sua vez deveria ouvir os profissionais de saúde.

A decisão negativa sobre o direito de vacinação pode ser enxergada como uma negligência de cuidados, pois, para os pais que decidem não vacinar, a percepção de cuidado é diferente dos adeptos à vacinação. Para o entendimento da recusa vacinal, é preciso fazer uma abordagem mais ampla, ir além da normatização biomédica e promover um diálogo mais amplo. Quando não há uma abordagem do pensamento coletivo, abriga a tormenta da consolidação do egoísmo cego e sem o respeito aos estudos científicos epidemiológicos.

\section{VACINAÇÃO COMPULSÓRIA}

$\mathrm{O}$ ato de se vacinar tem relevante apelo social e de âmbito de saúde pública, se justificando a imposição de sanções para aqueles que não observarem a citada medida. Como consta na mencionada decisão judicial as sanções aplicáveis são consubstanciadas, "basicamente, em vedações ao exercício de determinadas atividades ou à frequência de certos locais". Menciona ainda que "o Estatuto da Criança e do Adolescente na Lei n. 8.069/1990 $0^{6}$ prevê a obrigatoriedade da "vacinação de crianças nos casos recomendados pelas autoridades”, estabelecendo penas pecuniárias “àqueles que, dolosa ou culposamente,

\footnotetext{
${ }^{6}$ Lei n. 8.069/1990 < http://www.planalto.gov.br/ccivil_03/leis/18o69.htm> acesso em I2 de maio de 202I.
} 
descumprirem "os deveres inerentes ao poder familiar ou decorrente de tutela ou guarda" dos menores (art.14, § Iํ. e 249).

Obrigações específicas de vacinação estão previstas em atos infralegais, vigentes na Portaria I.986/200 7 do Ministério da Saúde, que abrangem algumas categorias profissionais, como trabalhadores das áreas portuárias e aeroportuárias ou tripulantes e pessoal dos meios de transportes."

O Plenário do Supremo Tribunal Federal (STF) decidiu que o Estado pode determinar aos cidadãos que se submetam, compulsoriamente, à vacinação contra a CovidI9, prevista na Lei $13.979 / 2020^{8}$. De acordo com a decisão, o Estado pode impor aos cidadãos que recusem a vacinação apenas as medidas restritivas previstas em lei como multa, impedimento de frequentar determinados lugares, fazer matrícula em escola, mas não pode fazer a imunização à força, de forma sistemática. Ficou definido que os estados, o Distrito Federal e os municípios têm autonomia para realizar campanhas locais de vacinação.

Esse entendimento foi firmado no julgamento conjunto das Ações Diretas de Inconstitucionalidade (ADIs) 6586 e 6587 , que tratam unicamente de vacinação contra a Covid-19, e do Recurso Extraordinário com Agravo (ARE) 1267879, em que se discutiu o direito à recusa à imunização por convicções filosóficas ou religiosas. O exame da matéria pelos Ministros resultou em vários destaques de posicionamento. O Ministro Luís Roberto Barroso, relator do ARE 1267879, destacou que, embora a Constituição Federal proteja o direito de cada cidadão de manter suas convicções filosóficas, religiosas, morais e existenciais, os direitos da sociedade devem prevalecer sobre os direitos individuais. Com isso, o Estado pode, em situações excepcionais, proteger as pessoas, mesmo contra sua vontade - como, por exemplo, ao obrigar o uso de cinto de segurança. Destacou ainda que não são legítimas as escolhas individuais que atentem contra os direitos de terceiros, frisando que a vacinação em massa é responsável pela erradicação de uma série de doenças, mas, para isso, é necessário imunizar uma parcela significativa da população, a fim de atingir a chamada imunidade de rebanho. O Digníssimo Ministro Barroso manifestou- se pela constitucionalidade da vacinação obrigatória, desde que o imunizante estivesse

\footnotetext{
7 Portaria MS I.986/200I <https://bvsms.saude.gov.br/bvs/ /comum/40.html> acesso em I2 de maio de 2021. ${ }^{8}$ Lei 13.979/2020 < https://www.in.gov.br/en/web/dou/-/lei-n-13.979-de-6-de-fevereiro-de-2020-242078735> acesso em $\mathrm{I} 2$ de maio de 202I.
} 
devidamente registrado por órgão de vigilância sanitária, esteja incluído no Plano Nacional de Imunização (PNI), obtendo sua obrigatoriedade incluída em lei ou tenha sua aplicação determinada pela autoridade competente.

Durante a discussão no plenário o Ministro Nunes Marques, que ficou parcialmente vencido, considerou possível a instituição da obrigatoriedade da vacina contra a Covid-ı́ pela União ou pelos estados, desde que o Ministério da Saúde seja previamente ouvido, e apenas como última medida de combate à disseminação da doença, após campanha de vacinação voluntária e a imposição de medidas menos gravosas, ainda que essa obrigatoriedade poderia ser implementada apenas por meios indiretos, como a imposição de multa ou outras restrições legais. Em relação à recusa em vacinar os filhos, o ministro afirmou que a liberdade de crença filosófica e religiosa dos pais não pode ser imposta às crianças, pois o poder da família não existe como direito ilimitado para dirigir o direito dos filhos, mas sim para proteger as crianças contra riscos decorrentes da vulnerabilidade em que se encontram durante a infância e a adolescência.

O ministro Alexandre de Moraes ressaltou que a compulsoriedade da realização de vacinação, de forma a assegurar a proteção à saúde coletiva, é uma obrigação dupla: o Estado tem o dever de fornecer a vacina, e o indivíduo tem de se vacinar. Para o ministro Edson Fachin, nenhuma autoridade ou poder público pode se esquivar de adotar medidas para permitir a vacinação de toda a população e assegurar o direito constitucional à saúde e a uma vida digna. "A imunidade coletiva é um bem público coletivo".

Segundo a ministra Rosa Weber, eventuais restrições às liberdades individuais decorrentes da aplicação das medidas legais aos que recusarem a vacina são imposições do próprio complexo constitucional de direitos, que exige medidas efetivas para a proteção à saúde e à vida. "Diante de uma grave e real ameaça à vida do povo, não há outro caminho a ser trilhado, à luz da Constituição, senão aquele que assegura o emprego dos meios necessários, adequados e proporcionais para a preservação da vida humana”.

Ao acompanhar os relatores, a ministra Cármen Lúcia defendeu a prevalência do princípio constitucional da solidariedade, pois o direito à saúde coletiva se sobrepõe aos direitos individuais, relatando que a Constituição não garante liberdades às pessoas para que elas sejam soberanamente egoístas. O ministro Gilmar Mendes observou que, 
enquanto a recusa de um adulto a determinado tratamento terapêutico representa o exercício de sua liberdade individual, ainda que isso implique sua morte, o mesmo princípio não se aplica à vacinação, pois, neste caso, a prioridade é a imunização comunitária. Também para o ministro Marco Aurélio, como está em jogo a saúde pública, um direito de todos, a obrigatoriedade da vacinação é constitucional. "Vacinar-se é um ato solidário, considerados os concidadãos em geral”. Em voto acompanhando integralmente os relatores, o presidente do STF, ministro Luiz Fux, ressaltou o empenho e o esforço dos ministros de forma a transmitir à sociedade segurança jurídica ao tema, frente a uma pandemia que provocou a morte de milhares de brasileiros. Fux observou que a hesitação quanto à vacinação é considerada uma das to maiores ameaças à saúde global, segundo a Organização Mundial de Saúde (OMS). A tese de repercussão geral fixada no ARE I267879 foi a seguinte: "É constitucional a obrigatoriedade de imunização por meio de vacina que, registrada em órgão de vigilância sanitária, tenha sido incluída no plano nacional de imunizações; ou tenha sua aplicação obrigatória decretada em lei; ou seja objeto de determinação da União, dos estados, do Distrito Federal ou dos municípios com base em consenso médico-científico. Em tais casos, não se caracteriza violação à liberdade de consciência e de conviç̧ão filosófica dos pais ou responsáveis, nem tampouco ao poder familiar".

Nas ADIs, foi fixada a seguinte tese: (I)“A vacinação compulsória não significa vacinação forçada, facultada a recusa do usuário, podendo, contudo, ser implementada por meio de medidas indiretas, as quais compreendem, dentre outras, a restrição ao exercício de certas atividades ou à frequência de determinados lugares, desde que previstas em lei, ou dela decorrentes, e tenham como base evidências científicas e análises estratégicas pertinentes, venham acompanhadas de ampla informação sobre a eficácia, segurança e contraindicações dos imunizantes, respeitem a dignidade humana e os direitos fundamentais das pessoas; atendam aos critérios de razoabilidade e proporcionalidade; e sejam as vacinas distribuídas universal e gratuitamente. (II) Tais medidas, com as

\footnotetext{
9 ARE $\quad{ }_{12} 67879 \quad<$ http://stf.jus.br/portal/jurisprudenciaRepercussao/verAndamentoProcesso.asp? incidente $=5909870 \&$ numeroProcesso $=1267879$ \& classeProcesso $=A R E \&$ numeroTema $=1103>$ Acesso em o9 de maio de 2021.
} 
limitações expostas, podem ser implementadas tanto pela União como pelos estados, pelo Distrito Federal e pelos municípios, respeitadas as respectivas esferas de competência.

\section{MOVIMENTO ANTIVACINA E RESPONSABILIDADE CIDADÃ}

Os fatores de influência na hesitação ou recusa vacinal são pessoais, políticos e

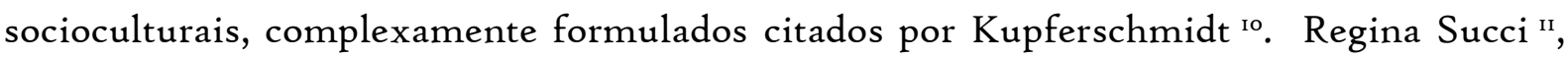
relata que população desconhece a verdadeira necessidade da imunização, sua segurança e eficácia; alimenta o medo de possíveis eventos adversos; possui experiências prévias negativas na saúde; e desconfia da seriedade da indústria de vacinas e do sistema de saúde.

O mais preocupante é que esses grupos são compostos, principalmente, por pais. Alguns podem expressar uma antipatia implícita à intervenção médica, com uma predileção por modos naturais ou alternativos de prevenção e tratamento de doenças. Em julho de 2019, um caso julgado pelo Tribunal de Justiça de São Paulo (TJ-SP) ganhou destaque nacional. O TJ-SP determinou que um casal do município de Paulínia vacinasse o filho de três $\operatorname{anos}^{12}$. Os genitores e representantes legais do menor apresentaram como conjunto de justificativas: o fato de a criança não estar na escola e, portanto, estar "longe de riscos de infecções", a adoção da "filosofia vegana" e a posição contrária a "intervenções invasivas”. Não vacinar é uma demonstração de um conjunto de valores. Outros ativistas incluem cidadãos em geral, profissionais de saúde e provedores de terapias alternativas.

Vários fatores socioeconômicos e educacionais podem estar relacionados com a adesão do movimento antivacina, Vasconcellos-Silva ${ }^{13}$ elucida em sua publicação que o padrão das crianças sub imunizadas é de ser filhos de mães jovens e solteiras, com baixa escolaridade e residentes em comunidades pobres nas adjacências de grandes centros. Em contraste, as crianças absolutamente não imunizadas eram filhos de mães casadas, com

\footnotetext{
ro The science of persuasion -BY KAI KUPFERSCHMIDT - SCIENCE28 APR 2017 : 366-369 $\langle$ https://science.sciencemag.org/content/356/6336/366〉 - Acesso em 2I de maio de 202I.

II Vaccine refusal --- what we need to know - Regina Célia de Menezes Succi - J Pediatr (Rio J). 2018;94:574--8I- DOI se refere ao artigo: <https://doi.org/ro.1or6/j.jped.2018.or.oo8 >Acesso em I9 de maio de 202I

${ }^{12}$ Acesso saúde online <https://acessosaude.online/justica-obriga-familias-a-vacinar-filhos/ >Acesso em Io de maio de 2021.

${ }^{13}$ Perigo do movimento antivacina: análise epidemio-literária do movimento antivacinação no Brasil Vasconcellos-Silva - Revista Eletrônica Acervo Saúde / Electronic Journal Collection Health | ISSN 21782091- REAS/EJCH | Vol.12(6) | e3088 | DOI:< https://doi.org/ro.25248/reas.e3088.2020 > Acesso em Io de maio de 2021
} 
alto nível de escolaridade, que residem em vizinhanças com renda acima da média nacional e contam com amplo acesso aos meios de comunicação de massa.

Conforme o Decreto no 78.231 de $1976^{14}$, é dever de todo cidadão submeter-se e aos menores dos quais tenha a guarda ou responsabilidade, às vacinações obrigatórias definidas pelo calendário nacional de imunizações.

Em indivíduos críticos, o modelo de crenças em saúde deveria determinar a tomada de decisão quanto a vacinação. Em termos calculáveis, a decisão de vacinar é equilibrada pelo risco compreendido de adquirir uma doença evitável pela vacinação e pelo risco percebido de complicações que esta imunização pode apresentar. Evidenciado pelo posicionamento mundial recentemente através da pandemia da Covid-I9 constata-se que a confiança nas vacinas e nas suas eficácias têm imprecisões, preocupações ou percepções errôneas sobre a imunização. A maioria das pessoas prefere buscar informações sobre a segurança das vacinas antes de serem aplicadas e reconhecem a internet como uma relevante fonte de informação, mas não necessariamente em sites técnicos e idôneos.

O Programa Nacional de Imunização (PNI) brasileiro é referência mundial, sendo pioneiro na disponibilização de vacinas de modo universal. Mas a principal influência e responsável pela adesão popular à vacinação ainda é o uso da mídia. O Programa Nacional de Imunização (PNI) é parte integrante do Programa da Organização Mundial de Saúde, com o apoio técnico, operacional e financeiro da UNICEF ${ }^{\text {Is }}$ e contribuições do Rotary Internacional e do Programa das Nações Unidas para o Desenvolvimento (PNUD) ${ }^{16}$.

Pelo Sistema de Informações do Programa Nacional de Imunização SI-PNI constata-se a possibilidade aos gestores envolvidos no programa uma avaliação dinâmica do risco quanto à ocorrência de surtos ou epidemias, a partir do registro dos imunes aplicados e do quantitativo populacional vacinado, que são agregados por faixa etária, em determinado período de tempo, em uma área geográfica. Por outro lado, possibilita também o controle do estoque de imunes necessário aos administradores que têm a incumbência de programar sua aquisição e distribuição.

\footnotetext{
${ }_{14}$ Decreto 7823I/1976 - < http://www.planalto.gov.br/ccivil_03/decreto/1970-1979/d78231.htm\#: :text=, $\% 200 \% 2 \% \mathrm{C}_{3} \%$ AAncias. $>$ Acesso em 12 de maio de 2021

is UNICEF < https://www.unicef.org/brazil/calendario-nacional-de-vacinacao-brasileiro> acesso em i3 de maio de 2021.

${ }^{16}$ PNUD < https://www.br.undp.org/> acesso em io de julho de 2021.
} 
Pelo Programa Nacional de Imunização (PNI) ${ }^{17}$ as coberturas vacinais têm declinado cerca de ro a 20 pontos percentuais Este evidencia a quantidade de doses aplicadas das vacinas: BCG, Hepatite B, Tríplice bacteriana (difteria, tétano e coqueluche) e Tríplice viral no período de 2015 a 2019. É nítida a redução do total de doses aplicadas nas vacinas contra a Hepatite $B$, já os dados referentes a BCG e a Tríplice bacteriana mostrando uma redução moderada. Isso era inesperado e veio acompanhado do aumento da mortalidade materno-infantil.

\section{CONCLUSÃO}

O ressurgimento de doenças que eram tidas como controladas por programas nacionais, exibe a dificuldade de adequação da saúde para com os meios de informação atual, que perpetuam dúvidas, medos e mentiras, em notícias chamadas de fake News, que podem ter contribuído para a redução da cobertura vacinal demonstrado pelo Programa Nacional de Imunização no Brasil.

Os esforços pela vacinação passam por estratégias que impactem a comunidades em sua nova forma de comunicar, incentivando a vacinação e transmitindo verdade, totalmente acessível. É importantíssimo esclarecer a necessidade da vacinação, mesmo sem a obrigatoriedade expressa em lei, mas legitimando a sua necessidade expressa. Esse estudo alerta para a importância de veicular informações corretas e que sejam de fácil acesso, visando minimizar os efeitos das notícias falsas pregadas pelo movimento antivacina.

$\mathrm{O}$ ato negacionista sobre a vacinação individual afeta todo o convívio social, conturba a cidadania, prevalecendo a manifestação de propagação de doenças não controláveis, gerando desequilíbrio a todo o condicionamento dos sistemas globais. Conviver, coexistir, participar de um grupo requer responsabilidade social, conceito de cidadania. $O$ indivíduo não promove pandemias em isolamento social. É necessário o poder de conscientização, de respeito aos demais, ao seu povo, sua localidade. Sem o bom convívio, a economia é prejudicada, a atuação profissional fica prejudicada, onde todos os elementos humanos entram em desequilíbrio. O homem é um ser social, conforme

\footnotetext{
${ }_{17}$ DADOS - PROGRAMA NACIONAL DE IMUNIZAÇÃO_ 〈http://pni.datasus.gov.br/consulta_gripe_ro.asp> Acesso em 21 julho de 2021.
} 
afirmado por Aristóteles e assim constatado na evolução humana. Todo homem é um ser que necessita de coisas e dos outros, sendo, por isso, um ser carente e imperfeito, buscando a comunidade para alcançar a completude. E a partir disso, ele deduz que o homem é naturalmente social.

\section{REFERÊNCIAS}

APS LRMM, Piantola MAF, Pereira AS, Castro JT, Santos FAO, Ferreira LCS.Eventos adversos de vacinas e as consequências da não vacinação: uma análise crítica. Rev Saude Publica. 2018; 52(40):1-13. Doi:https://doi.org/10.11606/si518-8787.2018052000384 Acesso em 12 de maio de 202I

FERREIRA SF. Crenças das mães em relação à vacinação. Rev Bras Enferm. 1984; 37(2):109-II5. doi: http://dx.doi.org/10.1590/So034-71671984000200005 8. Gomes LMX, Antunes KR, Barbosa TLA, Silva CSO. Motivos que levaram os idosos a não se vacinarem contra a influenza sazonal. Rev Pesquisa Cuidado é Fundamental Online. 2012; 4(3):256I-2569. Revista JRG de Estudos Acadêmicos -Ano III (2020), volume III, n.6 (jan./jun.) -, ISSN: 2595-I66I I8I - Acesso em I3 de maio de 202I.

IDOETA, Paula Adamo. A história que deu origem ao mito da ligação entre vacinas e autismo. Portal BBC. Disponível em: https://www.bbc.com/portuguese/geral-40663622. Acesso em:12 de maio de 2021.

JANINI, Tiago Cappi. Responsabilidade Civil do Estado nas Epidemias de Dengue. Revista Jurídica - UNICURITIBA, Curitiba, v.I,n.42,p.439-46r.2016. Disponível em:http://revista.unicuritiba.edu.br/index.php/RevJur/article/view/I5I6. Acesso em: 2I maio 2021.

REDAÇÃO. OMS considera movimento antivacina uma ameaça à saúde mundial. Portal Veja. Disponível em: https://veja.abril.com.br/saude/oms-considera-movimento-antivacina-uma-ameaca-a-saude-mundial/. Acesso em I2 de maio 2021. 
SBP. Imunizações e o impacto do movimento antivacinas na saúde pública em debate no ${ }_{20} 0^{\circ}$ Infectoped, em Salvador. Portal SBP. Disponível em: https://www.sbp.com.br/imprensa/detalhe/nid/imunizacoes-e-o-impacto-domovimento-antivacinas-na-saude-publica-em-debate-no-20o-infectoped-em-salvador/.

Acesso em:12 maio 2021.

SOUZA CJ, Vigo ZL, Palmeira CS. Compreensão dos pais acerca da importância da vacinação infantil. Rev Enferm Contemp. 2012: I(I):44-58. doi: http://dx.doi.org/ro.17267/2317-3378rec.viir.39_Acesso em I2 de maio de 2021.

TASCHNER, Natalia Pasternak. Por que o movimento antivacina não tem um pingo de sentido. Portal Saúde Abril. Disponível em <https://saude.abril.com.br/blog/cientistasexplicam/por-que-o-movimento-antivacina-nao-tem-um-pingo-de-sentido> Acesso em: I2 maio.de 202I. 